\title{
Correction to: Osteolipoma: a review of the literature and a rare case report
}

\author{
Hulya Cakir Karabas ${ }^{1}$ [D $\cdot$ Ilknur Ozcan ${ }^{1} \cdot$ Merva Soluk Tekkesin $^{2} \cdot$ Sabri Cemil Isler $^{3}$
}

Published online: 16 February 2021

(c) Japanese Society for Oral and Maxillofacial Radiology and Springer Nature Singapore Pte Ltd. 2021

\section{Correction to: Oral Radiology \\ https://doi.org/10.1007/s11282-020-00500-8}

In the original publication of the article, the reference citations were published incorrectly and it has been corrected.

The original article has been corrected.

Publisher's Note Springer Nature remains neutral with regard to jurisdictional claims in published maps and institutional affiliations.

The original article can be found online at https://doi.org/10.1007/ s11282-020-00500-8.

Hulya Cakir Karabas

hulya.cakirkarabas@gmail.com

Ilknur Ozcan

ilknurozcan1@gmail.com

Merva Soluk Tekkesin

merva.soluktekkesin@gmail.com

Sabri Cemil Isler

sabri.isler@istanbul.edu.tr

1 Department of Oral and Maxillofacial Radiology, Faculty of Dentistry, Istanbul University, Istanbul, Turkey

2 Department of Tumor Pathology, Institute of Oncology, Istanbul University, Istanbul, Turkey

3 Department of Oral and Maxillofacial Surgery, Faculty of Dentistry, Istanbul University, Istanbul, Turkey 